\title{
Prémios IUPAC 2021 em Química Analítica
}

Em 2019, a Divisão de Química Analítica da IUPAC estabeleceu dois prémios, a Medalha IUPAC em Química Analítica e o Prémio de Inovador Emergente em Química Analítica. A Medalha IUPAC em Química Analítica visa reconhecer a contribuição significativa para a Química Analítica e para investigadores com um histórico consolidado pelo número e qualidade das suas publicações, por estarem ativamente envolvidos em parcerias internacionais, bem como pelo seu compromisso na formação da próxima geração de químicos analíticos. O Prémio de Inovador Emergente em Química Analítica visa reconhecer o trabalho notável realizado por investigadores que estão no estágio inicial da sua carreira independente.

O primeiro vencedor da Medalha IUPAC em Química Analítica 2021 é Joseph Wang, Professor de Nanoengenharia na Universidade da Califórnia, em San Diego (UCSD), EUA. Os seus interesses incluem o desenvolvimento de biossensores eletroquímicos, nanomotores e nanorrobôs, sensores vestíveis (wearable), materiais extensíveis flexíveis, aplicações biomédicas de nanomáquinas, dispositivos para impressão, sensores baseados em nanomateriais, bioeletrónica, bioreconhecimento e diagnósticos clínicos, dispositivos microfluídicos (Lab-on-Chip), microfabricação, células de biocombustível, novas interfaces para eletroanálise e eletrocatálise, e sensores ambientais e de segurança.

O Prémio de Inovador Emergente em Química Analítica foi atribuído a Tsuyoshi Minami, Professor Associado na Universidade de Tóquio. As suas áreas de investigação baseadas em Química Analítica incluem o design e síntese de recetores artificiais, materiais semicondutores e nanomateriais, e fabricação de dispositivos para aplicações de deteção em soluções, fases sólidas e gasosas.

Mais informações disponíveis em iupac.org/ winners-of-the-inaugural-2021-iupac-analyticalchemistry-awards e iupac.org/the-2021-emerginginnovator-award.

$>$

\section{Bruno Machado}

brunofm@fe.up.pt

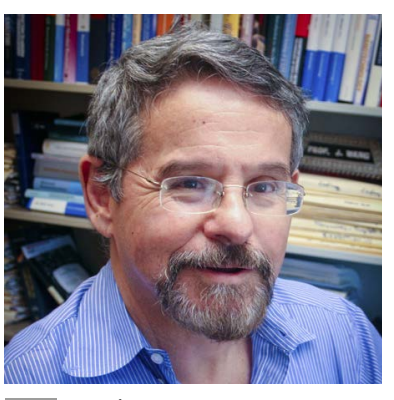

Joseph Wang

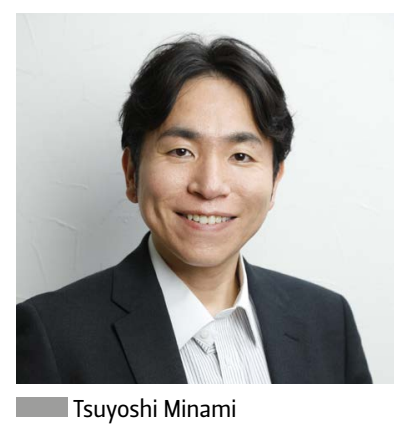

Tsuyoshi Minami

\section{Prémio Internacional IUPAC-Zhejiang NHU de 2021 para Avanços em Química Verde}

O Prémio Internacional IUPAC-Zhejiang NHU, atribuído a cada dois anos, foi estabelecido em 2019 para premiar quer químicos jovens em início de carreira quer químicos mais experientes com uma carreira consolidada e realçar a importância dos avanços em Química Verde.

Os destinatários do prémio de início de carreira em 2021 foram:

- Gabriele Laudadio, do Instituto de Investigação Scripps, em reconhecimento pelo seu trabalho em transformações químicas altamente seletivas e escaláveis que empregam fotões e eletrões como reagentes sem vestígios;

- Lichen Liu, da Universidade de Tsinghua na China, em reconhecimento pelo seu trabalho no desenvolvimento de estratégias para obter catalisadores de metais não nobres altamente seletivos e industrialmente viáveis;

- Jingxiang Low, da Universidade de Ciência e Tecnologia da China, em reconhecimento pelo seu 
trabalho no desenvolvimento e síntese de materiais fotocatalíticos para química verde.

o prémio de químico experiente foi atribuído a David Milstein do Instituto de Ciência Weizmann em Israel, em reconhecimento pelo seu trabalho no desenvolvimento de reações de síntese importantes, ambientalmente benignas e sustentáveis que geram ou consomem hidrogénio em condições amenas, sem produzir resíduos.

Os prémios foram entregues durante o Congresso IUPAC Virtual de 2021, que decorreu em agosto, num Simpósio especial agendado na área da Química para

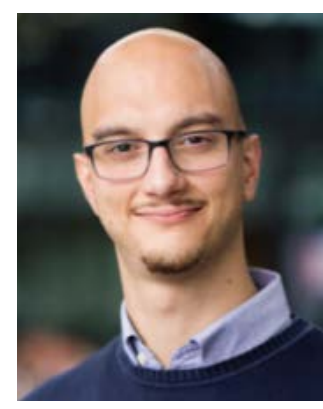

Gabriele Laudadio

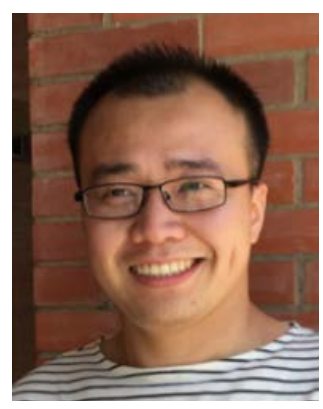

Lichen Liu a Sustentabilidade, em coordenação com o Comité Interdivisional de Química Verde para o Desenvolvimento Sustentável (Interdivisional Committee on Green Chemistry for Sustainable Development, ICGCSD) da IUPAC.

Os vencedores de 2021 do Prémio Internacional IUPAC-Zhejiang NHU irão também preparar um artigo de revisão para publicação numa próxima edição da revista Pure and Applied Chemistry.

$>$

\section{Bruno Machado}

brunofm@fe.up.pt

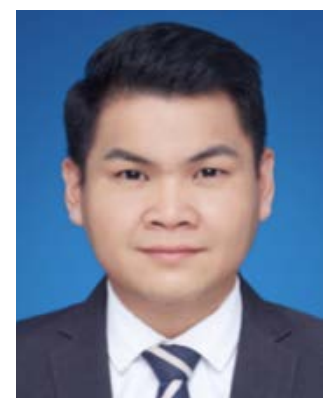

Jingxiang Low

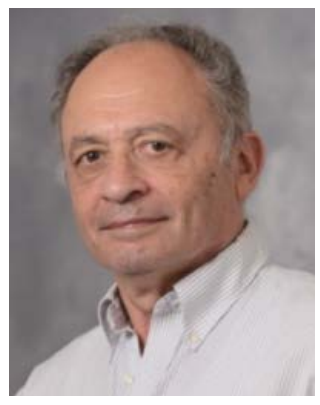

David Milstein

\section{Prémio Internacional IUPAC-Solvay para Químicos Jovens 2021}

A União Internacional de Química Pura e Aplicada e a Solvay anunciaram os vencedores do Prémio Internacional IUPAC-Solvay para Químicos Jovens 2021 para as melhores teses de Doutoramento na área da Química. Os cinco vencedores foram:

- Gabriele Laudadio (Itália), Eindhoven University of Technology: New synthetic methods enabled by photochemistry and electrochemistry in flow;

- Justin Andrews (EUA), Texas A\&M University: Corralling Electrons in Metastable Vanadium Oxides: Implications for Neuromorphic Computing, Electrical Energy Storage, and Photocatalysis;

- Kaibo Feng (China), University of Illinois at Urbana-Champaign: Late-Stage $\mathrm{C}\left(s p^{3}\right)-\mathrm{H}$ Hydroxylation, Amination, and Methylation in Nitrogen-Containing Molecules;

- Kelly Brown (Reino Unido), University of Strathclyde: Development of Electrochemiluminescent Sensors as Screening Tools for the Identification of Drug Species within Complex Matrices for Forensic Investigations;
- $\quad$ Austin Michael Evans (EUA), Northwestern University: Two-dimensional polymers and polymerizations.

Cada vencedor recebeu um prémio monetário e foi convidado a apresentar uma comunicação em painel no $48 .^{\circ}$ Congresso Mundial de Química da IUPAC sobre o trabalho premiado. Como o Congresso IUPAC deste ano decorreu virtualmente, os vencedores serão também convidados para o Congresso IUPAC 2023 que será realizado nos Países Baixos. Cada vencedor foi também convidado a submeter um artigo de revisão sobre os aspetos críticos do seu tema de investigação, que será publicado na revista Pure and Applied Chemistry.

Mais informações disponíveis em iupac.org/ winners-of-the-2021-iupac-solvay-international-award-for-young-chemists.

$>$

\section{Bruno Machado}

brunofm@fe.up.pt 